
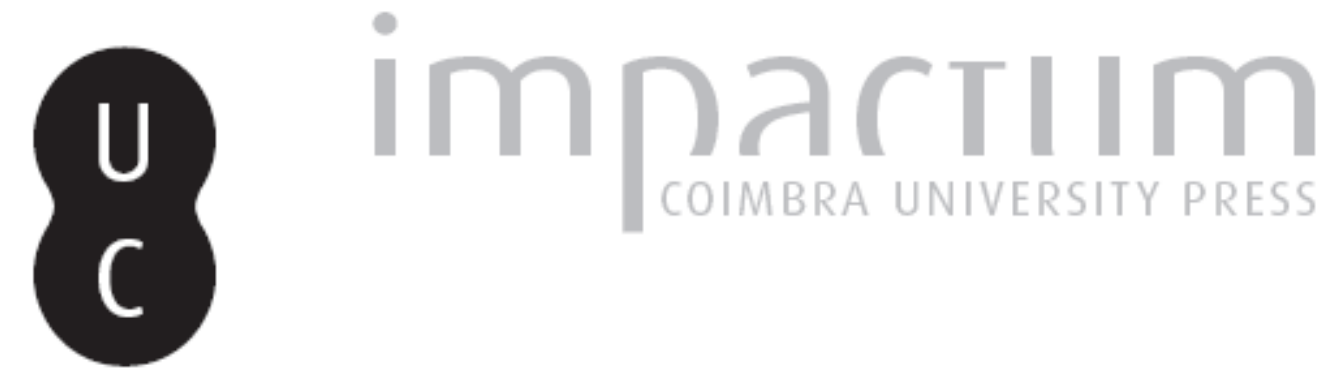

\title{
Tarâm-kübi: uma mulher de negócios no período Paleo-Assírio
}

Autor(es): Palma, Maria de Lurdes

Publicado por: Centro de História da Universidade de Lisboa

URL persistente:

URI:http://hdl.handle.net/10316.2/23728

DOI:

DOI:http://dx.doi.org/10.14195/0871-9527_20_14

Accessed : $\quad$ 26-Apr-2023 13:22:40

A navegação consulta e descarregamento dos títulos inseridos nas Bibliotecas Digitais UC Digitalis, UC Pombalina e UC Impactum, pressupõem a aceitação plena e sem reservas dos Termos e Condições de Uso destas Bibliotecas Digitais, disponíveis em https://digitalis.uc.pt/pt-pt/termos.

Conforme exposto nos referidos Termos e Condições de Uso, o descarregamento de títulos de acesso restrito requer uma licença válida de autorização devendo o utilizador aceder ao(s) documento(s) a partir de um endereço de IP da instituição detentora da supramencionada licença.

Ao utilizador é apenas permitido o descarregamento para uso pessoal, pelo que o emprego do(s) título(s) descarregado(s) para outro fim, designadamente comercial, carece de autorização do respetivo autor ou editor da obra.

Na medida em que todas as obras da UC Digitalis se encontram protegidas pelo Código do Direito de Autor e Direitos Conexos e demais legislação aplicável, toda a cópia, parcial ou total, deste documento, nos casos em que é legalmente admitida, deverá conter ou fazer-se acompanhar por este aviso.

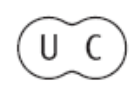




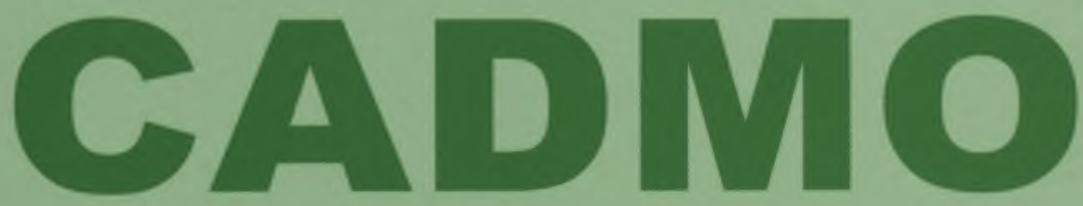

Revista de História Antiga

\author{
Centro de História \\ da Universidade de Lisboa
}

\title{
20
}

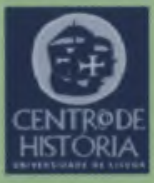

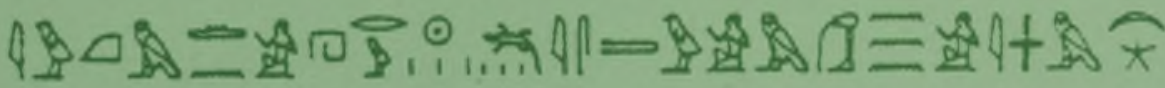

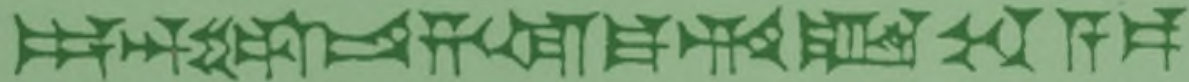

MHNIN AEI $\Delta$ E $\Theta E A ~ \Pi H \Lambda H I A \triangle E \Omega$ 


\title{
TARĀM-KŪBI: UMA MULHER DE NEGÓCIOS NO PERÍODO PALEO-ASSÍRIO
}

\author{
MARIA DE LURDES PALMA \\ Universidade de Lisboa \\ mlpalma@sapo.pt
}

«Diz a Innâya: assim (fala) Tarām-kūb[i]. (...) Porque é que não deixas de dar ouvidos a calúnias

e de me enviares cartas exasperadas?"

CCT 3, 24

\section{Resumo}

O comércio paleo-assírio desenvolveu-se entre a cidade-estado de Aššur e a Ásia Menor e envolveu a prata da região central da Anatólia, o estanho proveniente do Afeganistão, o ouro do vale do Indo, o cobre de Chipre, do Ponto e de Oman, e ainda os têxteis de fabrico mesopotâmico. Esta actividade mercantil terá constituído o elo de ligação entre todos estes centros produtivos, mais ou menos especializados, configurando uma interdependência económica num espaço alargado. As mulheres dos mercadores assírios desempenharam um papel activo na dinâmica económica e assumiram-se como gestoras de negócios, representando os maridos ou gerindo negócios próprios. Tarām-kūbi é exemplo destas mulheres gestoras.

Palavras-chave: Mulher assíria; História Social do Próximo Oriente Antigo; História Económica do Próximo Oriente Antigo. 


\section{Résumé}

Le commerce paléo-assyrien s'est développé entre la cité-état d'Aššur et l'Asie Mineure. L'argent de l'Anatolie centrale, l'étain de l'Afghanistan, l'or de l'Inde, le cuivre de la Chaîne Pontique, du Chypre et d'Oman, et encore les étoffes de production mésopotamienne sont les principaux produits. Cet activité aura constitué la liaison entre ces centres de production, plus ou moins spécialisés, en ordre à une interdépendance économique dans un cadre géographique très grand. Les épouses des marchands assyriens ont joué un rôle actif dans la dynamique de l'économie et elles s'engagent dans les affaires de leurs maris, elles représentent leurs maris et elles avaient des affaires propres. Tarām-kūbi est une de ces exemples extraordinaires.

Mots-ciés: Femme assyrienne; Histoire Sociale du Proche Orient Antique; Histoire Économique du Proche Orient Antique.

\section{Comércio paleo-assírio I (séculos $X X-X I X$ a. C.)}

\section{As trocas inter-regionais}

Milhares de tabuinhas retiradas das escavações arqueológicas da cidade de Kaneš (= Kültepe), provenientes de arquivos familiares privados de quatro a cinco gerações de mercadores assírios instalados nesta cidade, dão-nos conta de uma intensa actividade mercantil caravaneira, sustentada por empresas familiares, onde as mulheres desempenharam um papel crucial, e cujo auge se verificou desde os inícios do século XIX a. C. e até, sensivelmente, um pouco antes de c. de 1820 a. C. A arqueologia identificou 18 níveis de ocupação (em Kaneš), correspondendo o nível 8 (= Kārum II) ao período compreendido entre os século XX-XIX a. C., ou seja, aquele que nos interessa no âmbito deste trabalho. Os documentos escritos (cuneiforme em assírio antigo) revelaram-nos a correspondência privada da colónia comercial assíria, Kaneš, enviada para Aššur e vice-versa, e ainda para outros lugares da Ásia Menor, destinada a agentes económicos ou familiares de tais mercadores. De tão vasto conjunto epistolar sobressai, em particular, a informação relativa aos negócios em curso, aos processos de financiamento (actos de crédito, dívidas não resolvidas, prazos de vencimento), à organização do comércio (transporte...), mas também a assuntos domésticos, a contratos de casamento, textos 
de carácter jurídico, literário ou, até mesmo, escolar, entre outros. A partir de tal documentação, foi possível reconstruir uma florescente e intensa rede comercial, liderada pelos mercadores da cidade-estado de Aššur, que ligava regiões assaz distantes: Afeganistão, Irão, Mesopotâmia, Síria e Anatólia. Sendo a toponímia antiga da Turquia Central de localização extremamente difícil, apenas para Kaneš (= Kültepe) e Hattuša se pode apontar uma precisão geográfica; todos os outros topónimos concorrem entre si numa lógica de proximidade e de relação com os factos e o conteúdo histórico subjacente às diversas fontes (ver mapas 1 e 2). As cidades podem ser contíguas nos documentos, mas tal não deverá induzir-nos à conclusão da sua vizinhança física; podem, aliás, ser apenas terminais de rotas, as quais sempre atraíram os centros do poder quer político quer comercial.

Revelam os estudos(1) que à cidade-estado de Aššur, situada numa região parca em recursos naturais, se oferecia, todavia, uma situação geográfica privilegiada: entre o Tauro e a Babilónia (de norte para sul) e entre a Síria e a cadeia montanhosa dos Zagros (de oeste para leste), via confluir em si o cruzamento de percursos longos e plenos de diversidade, não só geo-económica, mas também étnica e linguística. De facto, desde o III milénio a. C., que a tal situação de favor respondeu o engenho mercantil assírio patrocinado pela política comercial dos soberanos de Aššur, quiçá com propósitos de influência no plano político conjugados com evidente prosperidade económica. No período médio da Idade do Bronze (c. XX-XIX a. C.), a Anatólia parece oferecer-nos um quadro de troca inter-regional, cujos protagonistas são simultaneamente as populações locais e os mercadores assírios. Produtores, consumidores e agentes/intermediários corporizavam uma economia assente num comércio de longa distância, apoiado em diversos centros económicos, e cuja gestão esteve a cargo dos mercadores de Aššur, sem concorrentes no contexto anatólico ${ }^{(2)}$. A rede comercial assíria ter-se-á sustentado num triângulo urbano vital, para além da região de Aššur: Kaneš, Durhumit e Purušhattum (todos com a qualificação de Kārum) $)^{(3)}$. O primeiro constituiu-se como a mais importante colónia comercial assíria na Anatólia, de acordo com os registos arqueológicos e fontes escritas até hoje interpretados; recebia directamente de Aššur o estanho e os têxteis, bens de procura elevada, cuja proveniência se situava em lugares diversos. O estanho, de origem afegã, entrava através da cidade de Susa (no actual Irão) na região aluvial mesopotâmica; a norte, uma outra rota comercial ligava - Afeganistão à cidade-estado de Aššur (via cadeia montanhosa dos 
Zagros), permitindo assim o seu envio para a colónia assíria de Kaneš. Desconhece-se quem controlava as vias comerciais que transportavam o estanho afegão até à Mesopotâmia, mas parece que não terão sido mercadores assírios ${ }^{(4)}$. Os têxteis (sobretudo a lã), produção mais ou menos generalizada no Próximo Oriente antigo e particularmente no sul mesopotâmico já num âmbito comercial e identificados com a designação de "acádios" (talvez indicando a origem dos mercadores que os transportavam até Aššur), gozavam de clientela abastada que os apreciava, na Anatólia. Assim, a presença de têxteis de outras regiões implicaria uma concorrência à produção local, aliás, bastante dificultada por preços que compensassem os custos de transporte. Só a grande qualidade dos têxteis provenientes de Aššur justificaria a sua importação. A partir de Kaneš, os têxteis seriam encaminhados para outras cidades da Anatólia, funcionando aquela como centro distribuidor. Da venda do estanho e dos têxteis obtinham os mercadores assírios o ouro (cuja origem é difícil de estabelecer, sendo a região do vale do Indo apontada como provável) e a prata (da Anatólia Central) utilizados como moeda de troca, seguindo uma parte muito significativa destes metais para Aššur, e destinada ao reinvestimento nos negócios.

O segundo centro, Durhumit, situado mais a norte, já na região do Ponto, nas margens do Mar Negro, rica em cobre, terá funcionado como um dos mercados abastecedores do Próximo Oriente ${ }^{(5)}$, principalmente a região anatólica e o norte mesopotâmico. Aqui chegavam o estanho e os têxteis vindos de Aššur (via Kaneš) e aqui eram negociados com o propósito de obtenção de cobre, o qual valia enquanto moeda de troca e/ou matéria-prima, alimentando também um comércio interno.

Purušhattum, situado a ocidente de Kaneš, controlava uma importante fonte de prata (Anatólia Central), constituindo este metal precioso a moeda de pagamento do estanho e dos têxteis recebidos de Aššur; por conseguinte, a prata chegava à cidade estado de Aššur e, quiçá, alcançava as cidades do sul da Mesopotâmia, utilizada como forma de pagamento dos têxteis "acádios" pelos mercadores assírios. Todavia, Purušhattum não revelou placas de argila (= tabuinhas), mas sim bullæ (impressões de selos) em dois edifícios, um que servia de palácio e outro de entreposto comercial.

De acordo com Barjamovic ${ }^{(6)}$, Durhumit e Purušhattum significavam "portas de entrada" para centros económicos aos quais os mercadores assírios não tinham acesso, na principal rota entre a Anatólia 
Central e a costa mediterrânea. Se, num primeiro olhar, os principais centros do comércio parecem situar-se numa zona relativamente restrita (c. de $200 \mathrm{~km}$.), densa de cidades cujas elites locais, abastadas, como já foi referido, consumiam grandes quantidades de têxteis e de estanho, uma abordagem geográfica compreensiva das vias comerciais pode conduzir-nos à percepção de um sistema inter-regional alargado de trocas e o comércio assírio poderá ter funcionado como link entre vários centros económicos da Anatólia. Por conseguinte, numa geografia política pautada pela existência de pequenos estados independentes, de centro urbano único e cujas chefias locais competiam entre si na procura do lucro sobre os bens comerciados, de realidades etno-linguísticas diferenciadas, o comércio parece ter constituído o grande elo de ligação e conferido unidade a uma região tão extensa que abrangia (incluindo os contactos externos) desde o Mediterrâneo até Turan (às portas da China), na direcção oeste-leste e do Ponto até Magan (Oman), na direcção norte-sul.

\section{Centro e periferia}

Falar de centro e periferia no contexto do sistema de trocas inter-regional, no qual o comércio paleo-assírio (séculos XX-XIX a. C.) se integrava, poderá não ser adequado. De facto, a região central do Próximo Oriente (do Mediterrâneo aos Zagros e do Golfo Pérsico ao Tauro/mar Negro) revela-se como uma unidade natural, no interior da qual alguns bens são necessariamente adquiridos fora da região mas gozando de complexas redes comerciais no seu interior ${ }^{(7)}$. O que parece emergir do estudo das fontes é a existência de centros de produção especializados em determinado produto e/ou matéria-prima - estanho (região afegã), cobre (Magan e região do Ponto/Mar Negro), ouro (vale do Indo), prata (Anatólia Central), têxteis (Mesopotâmia), cereais e vinho (desciam o Eufrates, vindos da região siría, até Mari) - os quais coexistiram sem conflito político-militar inter-regional significativo e com tratados comerciais que regulamentariam a relação mercantil. A cadeia montanhosa dos Zagros oferecia, sem dúvida, uma barreira natural entre a Mesopotâmia e o Elam (no actual Irão), o que, apesar de tudo, não impediu a circulação de bens (estanho) vindos do distante Afeganistão até Susa e Aššur. Todavia, a ausência de informação precisa relativa ao Irão e às culturas do vale do Indo (do II milénio a. C.) não permite conhecer nem a natureza nem a extensão do seu envol- 
vimento nas relações comerciais com o ocidente. Paralelamente aos centros de produção, parecem existir sociedades comercialmente especializadas: Aššur é o caso mais conhecido (mas não deverá ser o único), onde a importância da actividade mercantil se fazia sentir também no plano político, pois, na assembleia da cidade estavam representadas as colónias assírias da Ásia Menor com a presença do seu porta-voz oficial. A centralidade da cidade-estado de Aššur consiste na sua especialização no domínio económico, ou seja, é o espaço por onde fluem mercadorias de proveniência e destino diversos. Outras centralidades terão existido em inícios do II milénio a. C. no continente asiático; se o limite dos conhecimentos actuais não nos permite localizá-los, não devemos, por isso, deixar de colocar a hipótese da sua existência.

\section{Correspondência feminina e economia mercantil}

O comércio paleo-assírio desenvolveu-se, como já foi referido, através de empresas familiares, cujos negócios se repartiam por Aššur e colónias mercantis na Ásia Menor. Em muitos casos, o marido instalava-se em Kaneš e a esposa permanecia em Aššur com os filhos, cujas idades ainda não permitissem a sua participação activa na condução dos negócios da família. De facto, muitas vezes também os filhos se irão dispersar entre Aššur e a região anatólica concorrendo para o êxito das actividades mercantis familiares. A correspondência feminina, gerada naturalmente pela organização deste comércio que conduzia à separação física do casal em muitos casos, obedecia a determinada fórmula epistolar. Assim, os homens são mencionados antes das mulheres, salvo quando um homem se dirige a uma mulher mais velha ou quando os irmãos, no seio de uma mesma família, escrevem a uma irmã que seja sacerdotisa; também a esposa de um rico comerciante vê o seu nome anteposto ao dos seus interlocutores. A fórmula epistolar traduz assim a hierarquia social.

Da análise feita a esta correspondência se infere a importância económica que as mulheres (esposas, irmãs ou filhas) desempenhavam na economia mercantil paleo-assíria. De facto, eram elas que fabricavam os tecidos, considerados mercadoria nevrálgica neste contexto económico, com os quais se obtinham os metais preciosos na Anatólia; a matéria-prima, a avaliar pelo conteúdo de correspondência significativa, era, por vezes, conseguida na Anatólia, ou seja, era enviada 
pelos próprios mercadores assírios para as suas famílias, em Aššur, voltando depois já sob a forma de tecido. Esta situação faz prever que a obtenção da lã (a principal matéria-prima) não seria fácil em ambiente assírio, mas também se desconhecem quais os centros produtores/fornecedores na ou à região de Aššur. A tecelagem doméstica absorvia toda a mão-de-obra disponivel feminina: esposas, irmãs, crianças e criadas; confeccionados os tecidos, eram transportados para a Ásia Menor, mediante acordo com o transportador, não sendo raras as queixas das mulheres quanto às condições impostas por aquele. Acontecia, por vezes, que as mulheres não conseguiam satisfazer as exigências dos maridos, quer quanto à quantidade quer quanto à qualidade dos tecidos, o que dava azo a reprovações por parte destes, sempre mal toleradas pelo conjunto feminino. As fontes referem-se também a objectos e utensilios quotidianos (especialidades locais) apreciados pelos assírios.

A esposa recebia remessas enviadas pelo marido, às quais se juntavam, com frequência, presentes e jóias. Tinha uma bolsa própria, ou seja, mesmo havendo uma economia comum (do casal), a mulher detinha um pecúlio seu que defendia com firmeza, pronunciando-se contra qualquer utilização do seu capital pelo próprio marido ou seu representante. Algumas mulheres faziam render o seu dinheiro concedendo empréstimos, ganhando naturalmente com os juros. Ao marido competia assegurar parte do sustento da casa, saldar as suas (dele) dívidas. Todavia, são muitas as queixas que as mulheres registam na sua correspondência contra a avareza dos seus familiares. Com o dinheiro que recebem do marido e os seus capitais, a mulher assíria assegura a gestão da casa, ou seja, a educação e a alimentação dos filhos, bem como o sustento, o vestuário e a renovação da criadagem. Tem ainda de providenciar à reserva de cevada (a quantidade necessária até à próxima colheita), de fabricar a cerveja e de cuidar da manutenção da casa, assegurando as reparações do telhado e dos muros pela contratação de mão-de-obra específica.

A esposa era, também, no contexto económico, sócia do marido; nesta condição encontrava-se directamente implicada nos negócios daquele em Aššur, defendendo os seus interesses juntos dos seus "colegas banqueiros" e das autoridades locais. É à esposa que cabe a função de representar (substituir) o marido em todos os actos comerciais legais e fazer face às obrigações financeiras deste, ainda que ele tenha representantes no local. Neste quadro, é ela quem estabelece a taxa de exportação com o epónimo e recupera os créditos do seu 
marido; diligencia os documentos necessários às encomendas, prepara os documentos para as autoridades, e mantém o cônjuge informado do andamento de todos os seus negócios e operações financeiras. Supervisiona as mercadorias e os documentos, a fim de evitar os roubos; de facto, sempre que o marido enviava instruções aos seus representantes, fazia seguir também para a esposa uma "cópia" (ou seja, uma segunda "tabuinha" de igual conteúdo) de tais instruções para que ela pudesse controlar, efectivamente, a execução das suas ordens. Era a ela que chegavam as reclamações dos colaboradores de negócios do seu marido e a pressão das autoridades locais por causa das suas multas e dívidas.

\section{Tarām-Kūbi, esposa de Innāya, irmã de Imdīlum, filha de Šu-Lāban ${ }^{(8)}$}

\section{Contexto familiar}

Tarām-kūbi terá vivido entre os séculos XX e XIX a.C., na cidade-estado de Aššur, entre c. 1900-1814 a.C., tendo em conta que Innāya, seu marido, se instalou em Kaneš e se encontrava activo, de acordo com a lista de epónimos de Kültepe $(=K E L)$, no fim do reinado de Puzur-Aššur II e durante o reinado de Naran-Sîn de Aššur ${ }^{(9)}$. As "tabuinhas" dos arquivos privados dos mercadores assírios, trazidas à luz do dia pela arqueologia em Kaneš, dão-nos pouca informação acerca da identidade das mulheres de tais mercadores, o que, aliado à frequência de homónimos, dificulta a reconstituição das relações de parentesco. O nome de Tarām-kūbi aparece em vinte e cinco textos, sendo referenciada como esposa de Innāya num texto que não deixa qualquer dúvida: “(...) para Tarām-kūbi, esposa de Innāya, em Aššur» (10). Esta informação é extremamente importante (pela sua precisão) na análise da família de origem de Tarām-kūbi, pois, quanto a esta, foram levantadas cinco hipóteses; porém, a partir do estudo dos vinte e cinco textos que referenciam o seu nome, $\mathrm{C}$. Michel concluiu que Tarām-kūbi era a irmã mais velha de Imdilum, filho de Šu-Lāban (rico mercador assírio), o que aponta para este último também como pai de Tarām-kūbi. Quanto a esta família, há documentação relativa à sua actividade comercial em duas cidades, fora de Aššur: Kaneš e Durhumid. Coube ao seu irmão, Imdīlum, a direcção dos negócios do pai, após a sua 
morte (do pai), permanecendo em Kaneš durante um longo período findo o qual regressou a Aššur.

Tarām-kūbi casou na cidade de Aššur com Innāya, mercador da mesma cidade e do qual teve vários filhos, estando referenciados cinco nos arquivos da empresa comercial desta família: Aššur-rēși (o mais velho), Aššur-Taklāku, Puzur-Aššur, Šu-Sîn e Ikuppīya (o mais novo). Nascida no seio de uma grande família de mercadores, Tarām-kūbi perpetuou naturalmente o seu contexto social e económico através do casamento. Aššur, Kaneš e Durhumit constituíram, assim, os mais consistentes horizontes geo-económicos e familiares de Tarām-kūbi. Innāya (seu marido), filho de Elāli, continuou os negócios da família (estanho, ouro, prata e têxteis) e, após a morte de seu pai foi para Kaneš como representante da empresa familiar, permanecendo o seu irmão mais velho, Šu-kubum, em Aššur. Tarām-kūbi, porém, permaneceu em Aššur com os filhos mais pequenos, situação comum à primeira geração de mulheres cujos maridos geriam os seus negócios na Anatólia. Nada sabemos quanto ao seu fim, se terá ou não sobrevivido ao marido. Porém, as missivas conjuntas com a sua cunhada e dirigidas ao irmão Imdilum, solicitando que este regresse a Aššur (TC $1,5)$ e que contenha a sua ambição poderão reflectir a tentativa de evitar um desfecho semelhante ao de Innāya, logo, terá sobrevivido ao marido e manteve a sua participação em actividades mercantis. De facto, este terminou os seus funestos dias em Kaneš, depois de ter enveredado por negócios clandestinos de lápis-lazúli e de ferro (monopólios das autoridades da Anatólia). Com efeito, parte do comércio que percorria a Anatólia era exclusivo dos poderes políticos locais; todavia, e como forma de aumentar os seus rendimentos, encontramos registo de actividade comercial clandestina por parte de comerciantes assírios. Tendo sido descoberta a fraude, cedo chegou a sua ruína, pois, os seus credores reclamaram, de imediato, o reembolso dos seus empréstimos. De facto, denunciado e perseguido pelas autoridades anatólicas, Innāya foi preso e todos os esforços dos filhos para corrigir a situação financeira do pai se revelaram inúteis.

Quanto aos filhos de Innāya e Tarām-kūbi, todos estiveram envolvidos nos negócios do pai, de acordo com o carácter familiar comum às empresas comerciais assírias na Anatólia. Aššur-rēșī, o mais velho, permaneceu numa região mais a leste de Kaneš, no último troço da rota entre Aššur e esta colónia assíria; controlava a chegada das encomendas e mantinha o pai informado da situação política e económica da cidade-estado de Aššur e das transações comerciais efectuadas 
por aquele; por vezes, era acompanhado por um dos seus irmãos sobre quem tinha responsabilidade, na condição de irmão mais velho. Interveio sempre em defesa dos interesses do pai, respeitando escrupulosamente as instruções paternas. Aššur-taklāku, o segundo filho, estabeleceu-se na região de Zalpa ${ }^{(11)}$ (a sul de Harran?), mas viajava com frequência; correspondia-se com o irmão velho e interveio junto dos devedores de seu pai para obter o reembolso dos seus empréstimos. Preocupava-se com as acusações que recaíam sobre o pai, considerando-as perversas. Puzur-Aššur (o terceiro filho) realizava 0 transporte ente Aššur e a Anatólia e, por vezes, a pedido do pai, deslocava-se mais para oeste; entrava em questões, com frequência, com o irmão mais velho e com Šū-Sin (o quarto filho); preocupava-se com as disputas de seu pai com as autoridades assírias e anatólicas. Šū-Sin permaneceu junto de Aššur-rēọi (o irmão mais velho), sob as ordens deste, instalando-se mais tarde em Tagarama onde representava os interesses do pai. Por último, Ikuppiya, sendo ainda muito novo quando o pai partiu para Kaneš, ficou com a mãe em Aššur e, mais tarde, representava o pai localmente. Viajou para regiões mais afastadas; veio a revelar-se menos obediente às ordens do pai do que os seus irmão e acusou o seu tio Būr-Aššur (irmão de Innāya) de desviar os bens de Innāya.

\section{Correspondência de Tarām-kūbi para Innāya}

Tarām-kūbi enquadra-se no conjunto de mulheres que desempenhou um papel crucial no comércio realizado entre a cidade-estado de Aššur e a cidade de Kaneš, na Anatólia, nos inícios do II milénio a. C. Após a instalação do seu marido em Kaneš, assume a gestão da sua casa e os negócios da família, ou seja, representava a empresa do marido junto das autoridades e de outros mercadores ${ }^{(12)}$.

A sua correspondência faz menção aos produtos enviados por si e destinados à procura que as populações anatólicas representavam. Assim, os tecidos, de qualidade variada, por si produzidos e/ou talvez adquiridos a mercadores do sul da Mesopotâmia («tecidos acádicos») aparecem com frequência nas suas missivas dirigidas ao marido ( $B$ IN 6, 90; CCT 3, 23b; BIN 6, 46; CCT 3, 24; BIN 4, 91), os quais eram depois convertidos, mediante operação comercial, em ouro, prata e jóias que Innâya the enviava para Aššur, o que, a avaliar pelo conteúdo de alguma correspondência, nem sempre acontecia $(C C T 3,24)$. Por 
vezes, parece que não conseguia satisfazer os pedidos (de têxteis) de acordo com a frequência que o marido exigia (CCT $3,23 b)$. 0 estanho, outro produto deste importante comércio, aparece também mencionado na sua correspondência (BIN 6, 90). A par dos produtos legais, ou seja, aqueles que os mercadores assírios privados podiam transaccionar, encontramos a indicação dos produtos ilegais, isto é, aqueles cujo comércio era exclusivo das autoridades anatólicas: o ferro e o lápis-lazúli (CCT 3, 23b; CCT 4, 24a; BIN 4, 91).

$\mathrm{Na}$ sua correspondência, Tarām-kūbi manifesta com frequência a falta de dinheiro para providenciar às necessidades da sua casa (CCT 3, 23b; CTT 3, 25; CCT 3, 24) e/ou cumprimento do pagamento de dívidas às autoridades de Aššur $(C C T 3,23 \mathrm{~b}$, CTT 3,25$)$ ou obrigações de carácter religioso (CCT 3,24$)$, embora recebesse uma quantidade de ouro e prata superior à das outras mulheres ${ }^{(13)}$. Chega mesmo a referenciar a falta de alimentos, viver numa casa vazia e na fome terrível que assolou Aššur $(C C T 3,24)$. Aliás, a penúria da sua casa é tema recorrente em Tarām-kūbi.

Da sua correspondência inferem-se também situações difíceis para Innāya, na sequência da morte de um dos seus agentes comerciais-tamkärum (de nome Kura). Tarām-kūbi, juntamente com o seu filho mais novo, Ikuppiya, intervêm no sentido de defender os bens de Innãya depositados na casa de Kura (CCT 3, 24; CTT 3, 25; CCT 4, 24a; BIN 6, 46). Tarām-kūbi informou ainda o marido de situações relativas à compra de uma serva, cujo dinheiro para tal destinado não fora recebido, e que os objectos votivos para o deus Amurru se encontravam na casa de Elālī (sobrinho de Innāya), filho de Šu-kubum $(C C T 3,25)$.

Para além dos negócios que diziam respeito ao comércio dirigido pelo seu marido, estabeleceu actividades mercantis próprias, as quais geravam uma contabilidade pessoal, inferida de alguma correspondência e que Ihe permitia, em situações difíceis, fazer face a dívidas e compromissos do marido. Menciona a penhora de servas numa situação de pagamento de dívidas de Innäya $(C C T 3,24)$. Porém, quando tal acontecia, não deixava de solicitar, de forma enérgica, a Innāya a reposição de tal dinheiro (CCT 3, 23b; $\operatorname{CCT} 3,24)$.

Pelas missivas de Tarām-kūbi dirigidas ao marido perpassa uma «mágoa" pela ausência prolongada deste, em Kaneš; a esposa parece quase implorar, pois invoca argumentos de natureza religiosa e até afectiva, o regresso do marido a Aššur $($ CTT 3, 25). Mas a sua «mágoa" também transparece bem nas calúnias lançadas sobre si, a que Innāya parecia dar ouvidos $(C C T 3,24)$. 


\section{Correspondência de Tarām-kūbi para Imdīlum}

Imdīlum, irmão de Tarām-kūbi, estabeleceu-se durante algum tempo em Kaneš, após a morte do pai, assumindo a direcção dos negócios da família. A sua esposa, Šimat-Aššur, permaneceu em Aššur. Conhecem-se duas cartas que, em conjunto, Tarām-kūbi e a cunhada Šimat-Aššur, foram dirigidas a Imdillum. Pelo seu conteúdo, Tarām-kūbi continua a reclamar por não ser reembolsada do dinheiro que entregou aos representantes do irmão, pela compra de uma casa para a sua sobrinha (Ištar-bāšti, filha de Imdīlum), e do pagamento parcial dos tecidos que enviou a Imdilum (OrNS 50, 101). O pedido de regresso que implorou ao marido, aparece também numa carta ao irmão; porém, aqui mais legitimado - as duas mulheres consultaram os oniromantes, os adivinhos e os espíritos, através dos quais o deus Aššur lança o aviso: Imdillum ama demasiado o dinheiro e despreza a vida. Assim, é forçoso que o mercador regresse para salvar a sua vida $(T C 1,5)$. Poderá o regresso de Imdilum a Aššur, estar relacionado com o «aviso" do deus protector da sua Cidade? Talvez! Porém, não deixará de ser interessante o argumento invocado pela irmã e pela esposa.

\section{Mercancia e família}

A economia paleo-assíria teve na actividade mercantil a sua trave mestra. Da cidade estado de Aššur, espaço definidor da entidade política assíria nos alvores do II milénio a. C., partiam as caravanas transportando têxteis e estanho em direcção à Anatólia. De acordo com o material arqueológico e fontes textuais disponiveis, o maior centro comercial assírio da Ásia Menor residiu em Kaneš, seguido de Durhumit e Purušhattum. Com a venda dos têxteis e estanho eram obtidos o ouro e a prata que, enviados para Aššur, logo eram reinvestidos na compra de mais estanho e têxteis.

O comércio da Ásia Menor envolvia os recursos naturais minerais de que dispunha, a prata da região central da Anatólia e o cobre da região do Ponto e do Chipre, o estanho proveniente do Afeganistão, o ouro do vale do Indo, o cobre de Chipre e de Omã, e ainda os têxteis de fabrico mesopotâmico. A actividade mercantil paleo-assíria terá constituído o elo de ligação entre todos estes centros produtivos, mais ou menos especializados, configurando uma interdependência económica 
inscrita num espaço alargado, numa lógica económica de natureza "globalizante», cujos limites geográficos encontravam o mar Negro e o golfo Pérsico, no sentido norte-sul, e o Mediterrâneo Oriental e a entrada para a China, no sentido oeste-leste.

O carácter familiar das empresas comerciais assírias abriu espaço a uma participação feminina consistente e de destaque na dinâmica económica. Com efeito, a primeira geração de mulheres, cujos maridos se dedicavam às actividades mercantis na Anatólia, viu-se destinada à gestão dos negócios, em Aššur. Assim, além de constituírem a mão-de-obra disponível para a tecelagem, essencial nas trocas com a Anatólia, as mulheres participavam da responsabilidade comercial e financeira e do êxito das empresas lideradas pelo marido e desenvolveram negócios próprios. A família (esposa, irmãos, filhos) desta elite sócio-económica, que os mercadores assírios representaram nos séculos XX-XIX a. C., e com reconhecida importância política, gozou do estatuto de co-participante activo da empresa da qual fazia parte pelos laços do casamento ou de consanguinidade. Todavia, se o comércio paleo-assírio parece ter acusado um dinamismo notável, comparável a outros contextos económicos de desenvolvimento posteriores (e.g., as repúblicas italianas da Baixa Idade Média, ou as economias-mundo centradas em Lisboa e Sevilha no século $\mathrm{XVI}$ ), os lucros que gerava quando obtidos em paralelo com negócios ilegais, isto é, não permitidos a mercadores privados, podiam conduzir à ruína.

Com o marido a residir em Kaneš, dirigindo os negócios da família na Anatólia, Tāram-kūbi, a esposa do mercador assírio Innāya, permanecia em Aššur, confeccionava os têxteis, representava o marido junto das autoridades políticas da Cidade, desempenhando funções de "sócia", ou seja, em situação de paridade com os agentes comerciais do cônjuge. Revelou-se, assim, uma autêntica mulher de negócios, realizando actividades mercantis próprias geradoras de uma contabilidade pessoal que defendia com firmeza sempre que dela fazia uso para saldar dívidas do marido. A sua correspondência evidencia um estatuto social elevado, dominando a escrita, o mundo dos negócios e a "banca» (créditos, empréstimos...). O seu quotidiano foi também marcado pela mágoa da ausência prolongada do marido, cujo regresso solicita nas suas missivas. Aliás, a ambição desmedida de Innāya (comércio ilícito de lápis-lazúli e ferro) levou-o à prisão e arruinou a sua empresa. Estará esta fatalidade subjacente ao apelo de Tāram-kūbi e Šimat-Aššur dirigido a Imdīlum (irmão e esposo daquelas, respectivamente) e consubstanciado no aviso divino do deus protector da sua cidade 
- «tu amas (demasiado) o dinheiro e desprezas a tua vida!»? Imdilum parece ter dado ouvidos a tal aviso, pois regressou para junto da sua família em Aššur.

Em suma, mercancia e família funcionaram em uníssono no período paleo-assírio, pondo em evidência não só a capacidade dos homens de negócios de Aššur, mas também um dinamismo notável das suas mulheres, cujo trabalho produtivo (têxteis) alimentou o comércio, por um lado, e cujo desempenho na área da gestão empresarial concorreu para o desenvolvimento e afirmação de uma economia mercantil, por outro. 


\section{ANEXOS}

\section{Textos (correspondência de Tarām-kūbi para Innāya) ${ }^{(14)}$}

Fonte: C. MICHEL, Innāya dans les tablettes paléo-assyriennes, vol. II, Paris, Éditions des Textes, 1991, 11-23; idem, Correspondance des Marchands de Kanish, Paris, 2001, 400, 465469.

BIN 6, 90
F. $a-n a I-n a-a$
2. qi-bi-ma um-ma $T a^{*}-r a-a m-k u-b i-m a$
4. $[\mathrm{x}] \mathrm{TU}^{*} \mathrm{G}^{* \mathrm{hi}^{*}-\mathrm{a}} \mathrm{SIG}_{5}{ }^{\text {tim }}$ DIRI $[\mathrm{x}+] 2^{*} \mathrm{TU}^{*} \mathrm{Gi}^{*}-\mathrm{a} q a ́$-áb-li-[ú]-tim
6. $5^{*} \mathrm{TU}^{*} \mathrm{hi}^{*}-\mathrm{a} \check{s} a A-k i-d i-e$ $[\mathrm{x}+] 26 \frac{1}{2}$ ma-na AN.NA
8. $[\mathrm{x} a] t^{?} a-[\quad \ldots]$
Tr. $[\mathbf{x}] \mathbf{x}[\mathbf{x}] \check{s} u[\ldots] \mathbf{x}$
10. $[\mathrm{x}] \mathrm{GI}\left[\mathrm{N}^{*} \mathrm{~K}\right] \mathrm{U}^{*} \cdot \mathrm{BABBAR}^{*}[\ldots]$
R. mi-šál ANŠE
12. $\grave{u}^{*} m \imath^{*}-s ̌ a ́ l$ KÙ $\mathrm{U}^{*} \cdot \mathrm{BABB} A \mathrm{R}^{*}$

\section{$\mathrm{ANŠE}^{\text {hi-a }} i l_{5-q e ́}$}
14. 10 GÍN K[Ù.K]I ku-pu-ur-/šínim ù $n a-a ́ b-r i$-tám
16. a-șu-ha-ar-tim šé-bi $i_{4}-l a m$ na-áb-ri-/tum
18. $[l u] r a-b i_{4}-a-a t$ :

“'Diz 'a Innāya: ${ }^{2}$ assim (fala) ${ }^{3}$ Tarām-kūbi. ${ }^{4}[x]$ tecidos de excelente qualidade, ${ }^{5}[x+] 2$ tecidos de média qualidade, ${ }^{6} 5$ tecidos acádios, ${ }^{7}[x+] 261 / 2$ minas de estanho... ${ }^{10}[\mathrm{x}]$ sicl[os] de prata..., ${ }^{11}$ uma metade de (carga) de burro, ${ }^{12} \mathrm{e}$ a metade de prata; ${ }^{13}$ ele tomou os burros. ${ }^{17} \mathrm{Faz}$ me chegar ${ }^{14} 10$ siclos de ouro kupuršinnum e uma ${ }^{15}$ nabritum ${ }^{16}$ para a serva, que ${ }^{17}$ a nabritum ${ }^{18}$ seja grande". 
CCT 3, 23b

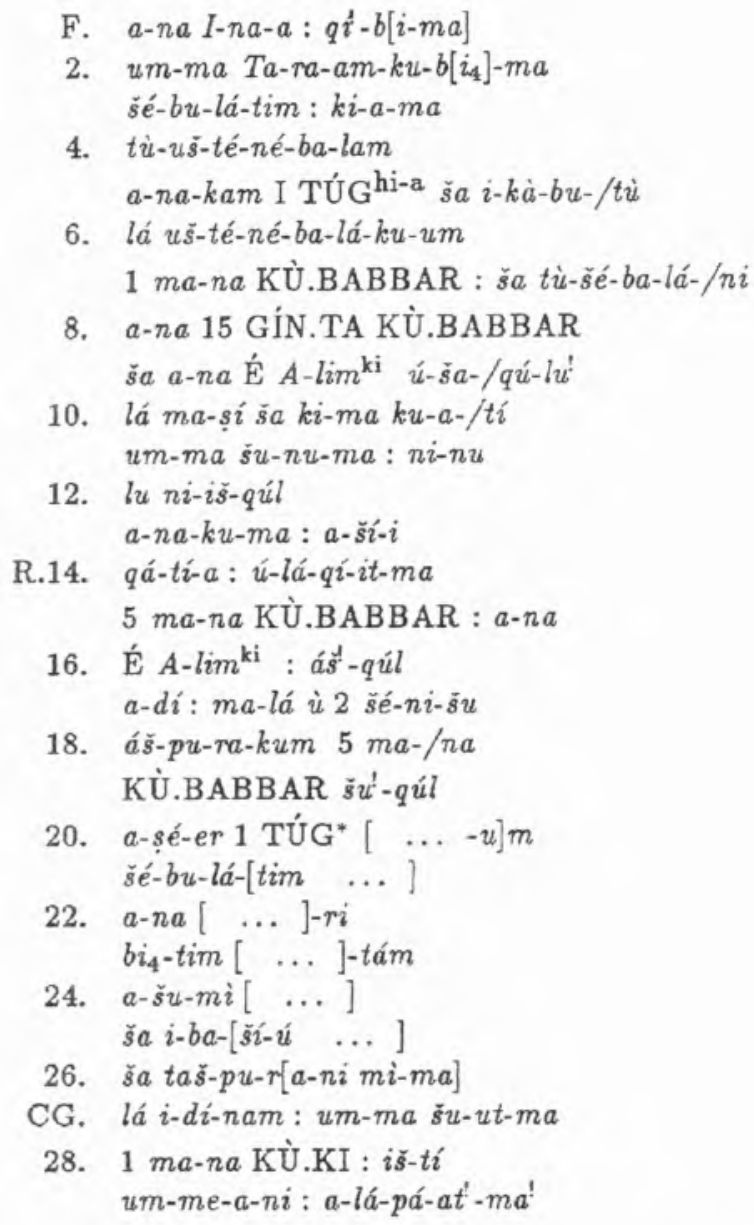

«Di[z] a Innāya: assim (fala) Tarām-kūb[i]. ${ }^{36}{ }^{3}$ Tu envias-me efectivamente sem cessar depósitos (de prata); mas, aqui não te posso enviar de cada vez (na volta) os tecidos que (são) pesados. ${ }^{7-19}(\grave{A}$ cerca) da mina de prata que tu fazes chegar, esta prata não é suficiente para as importâncias de 15 siclos por (pessoa) que eu devo pagar à autoridade da Cidade. Os teus representantes propuseram-me o seguinte: «Deixa-nos pagá-(lo)!» Mas eu, acumulei o ferro de meteorite (formando) a minha parte, e paguei 5 minas de prata à autoridade da Cidade. Eu escrevi-te várias vezes seguidas: "Paga então as 5 minas de prata!» ${ }^{20-29} \mathrm{Além}$ de um tecido ... os depósitos ... para .... a casa .... Em relação aos .... que se encontram ... e para os quais tu me escreveste, ele não me entregou [nada], (e) ele (disse-me) o seguinte: "Vou registar uma mina de ouro junto dos sócios capitalistas". 
F.* $[a-n a I]-n a^{*}-[a q i-b i-m a]$

2. [um-ma] Ta-ra-a[m-ku-bi-ma] É $K u$-ra É DA[M.GÀR-kà ? $\left.a^{?} a^{?}-i m^{?}\right]$

4. $\dot{\mathrm{E}}^{b i^{*}-t u m} i \check{s}$-tù $\left[m u-a-t i-s ̌ u^{?}\right]$ $k \dot{a}-n i-i k^{*}-[m] a$ a-na $\check{s}[\hat{i}-m] \dot{i}-i m$

6. $u k-t a-[n] a-l u-m u-s ̌ u$ a-ma-tim : a-na ši-mi-im

8. i-ta-ad-nu um-ma šu-nu-ma ù ú-nu-tám ni-ta-na-dí-in

10. ì šu-ma ša-im $\mathrm{E}^{b i-t i m}$ lá-šu : a-dí I-na-a i-lá-kà-ni

12. lu kà-ni-ik lá ni-pá-té $\check{S} u-k u-b u-u m$ A-hu-qar ù me-er-ú-šu

14. $u \check{s}-t a-n a-h u-z u-\check{s} \check{\imath}$ um-ma šu-nu-ma e ta-me-šs $[a]$

16. $\check{s} a K u-r a$ a-na ši-mi-im li-di-nu-ma: šu-a-um $\mathrm{E}^{b i}-s u$

18. li-zi-iz $\dot{u} I \check{s}_{4}-t a ́ r-D I N G I R-s ̌ u$ $a-b u-t a-a ́ s-n u-m a: i-z a-a z$

20. $[n] i^{*}-n u^{*}: a-n a ~ \check{s} a-z u-z a-t i ́-k \grave{a}$ [ni]-ta-na-lá-ak-ma

22. $[i-z i]-z a-a m$ lá $i-m u-u ́$

[a-ša $K u]$-ra-ma ú-lá ni-za* $a\left[z^{*}\right]$

24. [x m]a-na KÙ.GI : $i-n a$ $[\check{s} a \dot{E}]-k \dot{a}: \check{s ̌ i}-i p-k \dot{a}-t \hat{i}-s ̌ s-n u$

26. [É $K u]-r a: a-n a$ ši-mi-im

R. $[a-n] a$ En-na-sú-in DUMU Ku-ra-ra

28. [i]-ta-ad-nu: I-ku-pi-a a-na En-na-sú-in : i-lik-ma

30. iq-bi: um-ma šu-ut-ma I-na-a $e-b a-a r-k \grave{a}: e-z i-i b$

32. lá ta-ša-am-ma: lu-mu-un li-bi-im : lá té-pá-ší um-ma šu-ut-/ma

34. ธ̌a da-am-qi-iš e-pu-šíni-ma KÙ.BABBAR : i-na șé-ri-a : im-qú-tù 
36. $a-\check{s} a-a m-m a$ uे $a-\check{s} a-a m i \check{s}-t a-a m$

Lá-ma-sí $a-n a$ Ú-șí-ur-ša-a-šùr

38. ì DUMU I-na-a: ta-lik-ma um-ma ši-it-ma: i-zi-za-ma

40. KÙ.BABBAR : É DAM.GÀR lu $n i-i l_{5}-q e ́-/ m a$ qá-áb-li-tám: lu nu-ri

42. $\dot{u}-u l a-t \grave{u}-n u-m a: e-r i-a-k u^{!}$ lu gi-mi-lams : lá $i-m u-u ́$

44. En-na-ma-num: ú-ša-hi-zi-ma a-na A-lim ${ }^{\mathrm{ki}}$ ta-lik-ma

46. KÙ.BABBAR : ša É En-na-ma-nim i-ba-ši-/ú ù $\check{a} a$ a-na I-ku-pí-a:a-na

48. [n]a-ru-qi*! $-i m: t a-d i-n u: t a-t a-b a-[a l]$ $[a]-n a \quad a-h i-k \dot{a}: \dot{u} e[\mathbf{x}]-r u-[\mathbf{x} \quad \mathbf{x}]$

50. [ ... ] $i-z a-z u[\ldots]$

CG. [i] h-da-ma: $k u-u \check{s}-d a-m a \dot{\mathrm{E}}^{b \dot{s}-i t}-k \grave{a}$

2'. $\quad[\mathrm{x} \mathrm{x}]$ pá-ru-rú $a-u m^{\prime}-m i-a-n i$ ù ša-zu-[za-tí-kà] [t] $\dot{u}-d i-n a-t i ́-n i: n u-l a ́-q i-i t-m a: a-n a$ KÙ.BABBAR

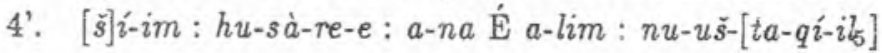

"[Diz a I]nnā[ya]: [assim (fala)] Tarā[m-kūbi]. ${ }^{3-12}$ Em relação à casa de Kura, [eles (querem) vender] a casa. Desde [a sua morte], a casa está sob selo judicial, e para [ven]da, não se cessa de a mostrar. Eles colocaram à venda os servos, e disseram o seguinte: "Nós venderemos enquanto for necessário, igualmente os móveis, e se não houver comprador para a casa até à chegada de innāya, que ela fique selada, nós não a abriremos." 13-19Šu-Kūbum, Ahu-(wa)qar e os seus filhos não cessam de the dar conselhos, dizendo: "é necessário vender o (...) de Kura, mas a sua própria casa deve ficar sua; Ištar-ilšu intercederá por eles." ${ }^{20-36}$ Nós, nós vamos continuamente até junto dos teus representantes, mas eles recusaram agir (dizendo): "Nós não faremos nada pelos familiares de Kura". A família de Kura vendeu [x mi]nas de ouro provenientes dos seus investimentos [a] Enna-Sîn, filho de Kurãra. Ikuppia foi até junto de Enna-Sîn e disse-(Ihe) isto: "Innãya (é) teu colega, esquece o assunto, não compres, não me causes aborrecimento", mas ele respondeu o que se segue: "Já que ele me tratou bem e assim que a prata chegar, (então) comprá-los-ei, verdadeiramente os comprarei.» E eles comprou-os! ${ }^{37 .}$ ${ }^{50}$ Lamassĩ foi até junto de Ușur-ša-Aššur e do filho de innāya e ela disse isto: "Agi para que nós emprestemos a prata para a casa de um credor-tamkārum e que nós esvaziemos o cofre pequeno, ou então, vós mesmos, esvaziem-no, é um favor!’ Eles recusaram. Ennam-Anum informou-a disto, e logo que ela 
chegou à cidade de Aššur, ela levou a prata que se encontrava na casa de Ennam-Anum e que tu tinhas dado a Ikuppia para o seu contrato naruqqum [...] ao teu irmão e [....] eles se seguram (lacuna).

11-4 Velai para juntá-lo e [eles não se devem] separar da tua casa. Nós juntámos o bronze para a oferenda da jov[em mulher] e os nossos alfinetes-tudittum em troca da prata (equivalente) ao preço do lapis-lazuli, nós pagámo-los à autoridade da Cidade".

\section{BIN 6, 46}

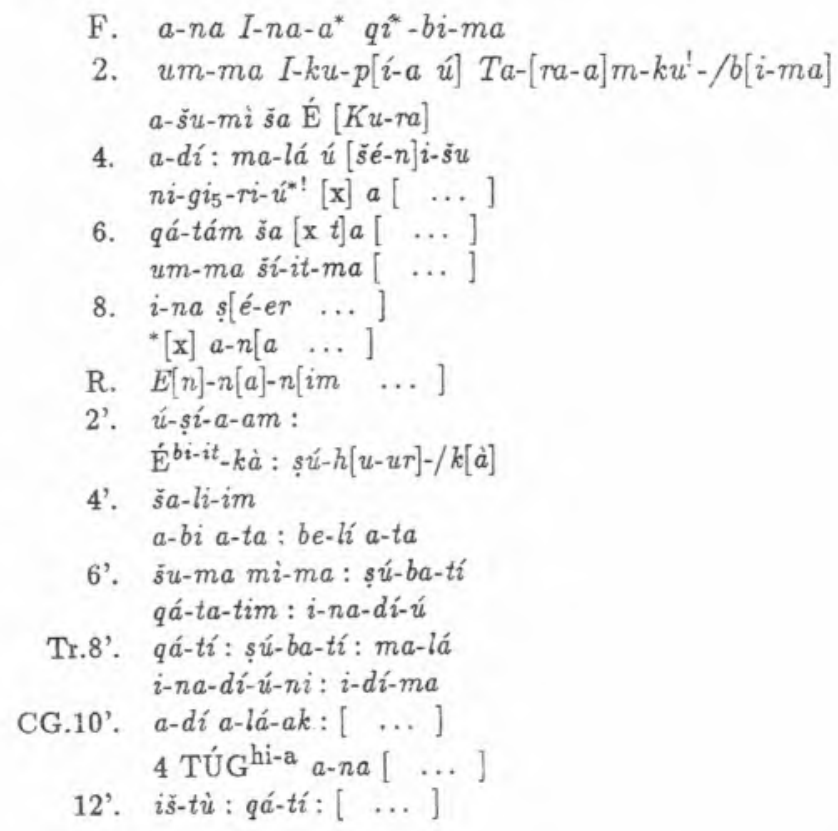

«'[D]iz a Innāy[a]: '2assim (falam) Ikuppīya e] Ta[rām]-kūbi. ${ }^{3} E m$ relação à casa de [Kura] ${ }^{5}$ nós temos promovido diligências ${ }^{4}$ por diversas vezes ... ${ }^{6}$ a parte ..... ${ }^{7}$ ela exprimiu-se assim: ".... ${ }^{8} \mathrm{com}$ a condição de ...." (lacuna) ${ }^{1}$ Ennänum .... ${ }^{2}$ Saíu...${ }^{3}$ a tua casa e o teu filho ${ }^{4}$ passam bem. ${ }^{5} \mathrm{Tu}$ 'és meu pai, tu és o meu mestre. ${ }^{6}$ Se ${ }^{7}$ eles depositam ${ }^{6}$ todos os tecidos ${ }^{7}$ do fiador, ${ }^{9}$ deposita ${ }^{8}$ os meus lotes de tecidos do mesmo modo ${ }^{9}$ que tem havido os depósitos (de tecidos). ${ }^{10}$ Até à chegada .... ${ }^{11} 4$ tecidos para ... ${ }^{12}$ minha parte....". 


\section{CCT 3,25}

F. a-na I-na-a qi-bi-ma um-ma Ta-ra-<am>-ku-<bi>-ma

2. a-wa-tám : ša É $K u-r a \bar{s} a$ tù'-wa-du-ú ta-bu-a-at : KÙ.BABBAR iš-tí pá-nim-ma

4. šé-bi-lá-ma: țup-pu-šu a-na $\mathrm{E}^{t i}-k \dot{a}$

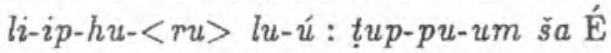

6. En-na-sú-in : É $\check{S} u$-be-lim pá-qí-id

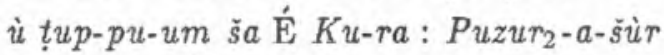

8. $\grave{u}-k \dot{a}-a l: \mathrm{K} \dot{U} . \mathrm{BABBAR} i-n a$ pá-ni-kà šé-bi-lá-ma: $i$-na É $k u-n u-k i-k a ̀$

10. li-ni-dí KÙ.BABBAR $a-n a$ šé-bu-li-im $m i ̂-m a: ~ l a ́ ~ t a-p a ́-l a ́-a h: \mathrm{KÙ.BABBAR}: a-n a$

12. $\dot{\mathrm{E}}^{b i-t i_{-}} k \dot{a}-m a: e-r a-a b: \check{s} a-t u m$ $\check{s} a-n a-a t \mathrm{KU} . \mathrm{BABBAR}$ šé-bi-lá-ma

14. ú-țá-tám a-pá-ni-kà li-iż-pu-/ku-ni-kum ba-pí-ra-am ša e-pu-ša-ku-ni

16. il

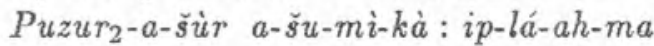

18. um-ma ni-nu-ma mi-ma lá ta-pá-lá-ah a-wa-tám : ku-bu-ús-ma ú a-wi-lúm

R.20. šé-ep-šu : a-na A-lim ${ }^{\mathrm{ki}} \quad$ li-iq-ru-ba-/am ú-sá-li-šsu-ma: a-wa-tám

22. ig-mu-ur a-pu-tum ki-ma țup-pá-am ta-áš-me-ú : al-kam-ma

24. e-en $: A-s ̌ u ̀ r ~: D I N G I R-k \grave{a} \grave{u}<i>-l i b i_{4}-/ t i ́-k \grave{a}$ $a-m u-u r:$ ú $a-d i ́: b a-a l-t a^{\prime}-k u^{*}-n i$

26. e-né-kà lá-mu-ur: du-lu-um ${ }^{! *} a-n a l i-b i_{4}-/ n i$ $e-t a-r a-a b: k i-t a-a m:$ ú $i s-r a-a m^{!}$

28. $a-n a{ }^{\mathrm{d}}$ MAR.TU ${ }^{i m}$ š DUMU $\check{S} u-k u-b i-i m$

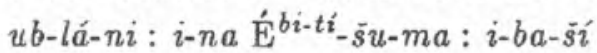

30. țup-pá-am : šé-bi-lá-šu-ma: kit-ta-a-am ù $i \grave{s}-r a-a m: l i-d \hat{i}-i n-m a: i-n a$

32. bi-tí-kà : li-bi-ší: a-šu-mi : am-tim $A$-šùr-ták-lá-ku iš-pu-ra-ma i-na tup-pi-šu

34. $\frac{1}{3} m a-n a$ KÙ.BABBAR $a-n a$ E-lá-lí DUMU $\dot{S} u-k u-b i_{4}-i m$ a-dí-in : am-tám : šu-ub-ri-tám li-iš-/a-ma $a^{!}-k i$-im 
36. DUMU $\check{S} u-k u-b i_{4}-i m$ : ás̆-al-ma

um-ma šu-ut-ma KÙ.BABBAR $A$-šùr-ták-lá-ku lá i-dí-/nam

38. țup-pá-am šé-bi $i_{4}-l a ́$-šu-ma: am-tám

li-iš-a-am-ni-a-tí

CG.40. bi-tám ša țé-hi É $\mathrm{E}^{t i}-n i$ : qá-ra-be-e Puzur 2 -a-šùr

$i \check{s}-a-m a-k u m$ ša É na-ga-ri-im kà-lá-šu

42. i-lá-qét-ma: iš-tí pá-nim-ma: ú-šé-ba'-lá-kum

«Diz a Innāya: assim (fala) Tarām-kūb[i]. ${ }^{2 \cdot 8} \mathrm{Em}$ relação ao assunto da casa de Kura que tu negociaste, ele foi anulado. Faz chegar a prata pelo próximo (portador) e que se faça voltar as suas tabuinhas para a tua casa. A tabuinha da casa de Enna-Sîn foi confiada à firma de Šu-Bēlum e Puzur-Aššur (quanto a ele) ${ }^{8}$ possui a tabuinha de Kura. ${ }^{9 \cdot 16} \mathrm{Faz}$ chegar a prata pelo teu próximo (portador) para que seja depositado na tua casa-forte. (A que se destina) a prata a enviar, não tenhas receio algum, a prata entrará na tua própria casa. A estação chegou. Faz-me chegar a prata para que possa recolher os cereais antes da tua chegada. (Em relação) ao pão de cerveja que eu te tinha preparado, ele ganhou ranço. ${ }^{16-22}$ (Quanto) à casa de Kura, Puzur-Aššur tinha receios em relação a ti, então nós dissemos-lhe isto: "Não tenhas receio, deixa cair o negócio, e que o homem se aproxime da Cidade (d'Aššur)". Eu tinha-Iho pedido e ele aveitou o negócio. ${ }^{22-32}$ Peço-te isto, logo que tenhas entendido a minha tabuinha, vem, olha na direcção de Aššur, o teu deus e o teu património, e enquanto eu viva, que possa ver os teus olhos. A miséria entrou em nossa casa. O kitum e o cinto que o filho de Šu-Kūbum transportou para o deus Amurrum encontram-se na sua própria casa. Envia-lhe uma tabuinha para que ele dê o kitum e o cinto para que fiquem em tua casa. ${ }^{32 \cdot 39} \mathrm{Em}$ relação à serva, Aššur-taklaku escreveu-me: "Segundo (a instrução dada) na sua tabuinha, eu enviei $1 / 3$ de mina de prata a Elālī, filho de Šu-Kūbum, para que ele te compre uma serva de Šubartu." (A este respeito) interroguei o filho de Šu-Kūbum (que me respondeu) isto: "Aššur-taklaku não me deu a prata!» Envia-Ihe uma tabuinha para que ele nos compre a serva. ${ }^{40-42}$ Puzur-Aššur comprou-te a casa próxima da nossa (...). Ele tomará todo o complexo da casa do carpinteiro e ele enviar-te-á, pelo próximo (portador, o contrato de venda da nossa nova casa)." 
CCT 3, 24

F. $a-n a I-n a-a$ qi-bi-m[a]

2. um-ma Ta-ra-am-ku-bi-ma ta-áš-pu-ra-am um-ma a-ta-ma

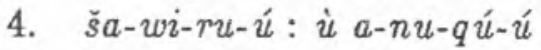
$\check{s} a \quad i-b a-s ̌ i-u ́-n i: \check{s} a-s ̦ i-r i$

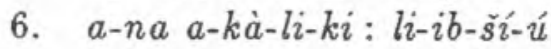
$k e-n a^{!}-t i m-m a: \frac{1}{2} m a-n a \mathrm{KÙ} . \mathrm{GI}$

8. DINGIR-ba-ni: $t \grave{u}-s ̌ e ́-b i-l a m$ $a-i$-ú-tim $[\check{s}] a-w i-r i$

10. ša té-zi-ba-ni $i-n u-m i$ tù-ús-ú KÙ.BABBAR 1 GÍN

12. ú-lá té-zi-ba-am I Étám tù-lá-qí-it- $[m a]:$ tù-šé-șí

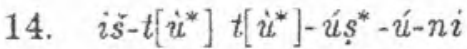
$d a-n u-t u m[b u-b u]-t u m$

16. i-n[a]A-lim ${ }^{\mathrm{ki}}$ : ù-lá še-am $1 \mathrm{SILA}_{3}$ : té-zi-ba-am : še-am

18. $a-n[a]$ ú-kúl-tí-ni: áš-ta-na-am* ù tap-hit

20. i-na it-[ ... ] $a-d \dot{\imath}-i n-m a[l u]-u ́$

22. qá-tí-<<a>> : ag-da-ma-ar

R. ì $a-n a$ É $A-l i m^{\mathrm{ki}}$ : $a-n a[\check{s} e-i m x]$

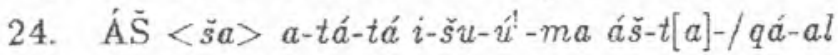
mi-num: $r i-i b-s ̌ u$

26. $\check{s} a$ ta-ás-ta-na-pá-ra-ni $a-n a \quad a-k \dot{a}-l i-n i-\dot{i}$

28. lá-šu: ni-nu: $r i-i b-s ̌ i ́$ né-ta-na-pá-ás̆ $\check{s} a$ i-qá-tí-a

30. ib-šsi-ú : ú-lá-qí-it-ma uš-té-bi $i_{4}-l a ́-k u m: u_{4}-m a-a m$

32. i-bi-tim: e-ri-im: wa-ášs-ba-ku sa-tum : ša-na-at

34. i-hi-id-ma: me-eh-ra-at

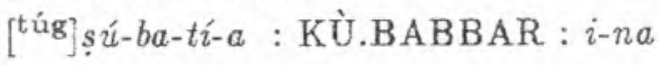


36. $[\check{s} a] i-q a ́-t i ́-k a ̀-m a: i-b a-\breve{s} i-u ́$ $\check{s} e ́-b i_{4}-l a m-m a: \check{s} e-a m 10$ ÁS

38. lá-ášs-am: a-šu-mì : tup-pí-im ša A-š̀ur-i-mi-tí DUMU Ku-ra

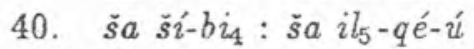
$\hat{\mathrm{E}}^{t a ́ m}: \dot{u}-\bar{s} a-a h-d \hat{i}-i r-m a$

42. a-ma-tim: ú-kà-tí-ma $\check{s} a-z u-u ́ z-t a-k a ̀ a-a-w a-t a ́ m$

44. ig-mu-ru-ma

CG. $\frac{2}{3} m a-n a \mathrm{KU} \cdot \mathrm{BABBAR} a s^{\star}-t a-q a l: a-d i ́ t a-l a ́-k \dot{a}-/ n i$

46. lấ i-ra-ga-am: i-na a-lá-ki-ká ta-ta-ú-wa: mi-šu-um: ta-ki-li

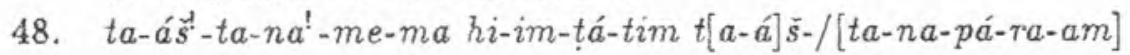

"Diz a Innāya: assim (fala) Tarām-kūb[i]. ${ }^{3-13}$ Tu escreveste-me o seguinte: "Guarda as pulseiras e os anéis que são (aqui), que eles sirvam para o teu sustento". Na realidade, tu fizeste-me chegar 1/2 mina de ouro (por) IIT-bāni. Quais (são então) essas pulseiras que tu me deixas-te? Logo que tu partiste, tu não me deixaste (senão) um siclo de prata. Tu desguarneceste a casa [e] tu tens (tudo) vazio. ${ }^{14-38}$ Desde que tu p[a]rtiste, uma fome [terrivel] (instalou-se) na Cidade (d' Aššur) (e) ${ }^{17}$ tu não me deixaste cevada senão um litro. Eu tenho, sem cessar, necessidade de comprar cevada para a nossa alimentação, e em relação à colecta do templo para a qual eu dei um emblema num ..., certamente, eu terminei o que tinha em mãos e eu paguei à autoridade da Cidade para $\mathrm{x}$ medidas șimdum [de cevada] (que) Atata possui. Qual é então a extravagância pela qual tu não cessas de me escrever? Não há nada para o nosso sustento. (Mas) nós, (tu crês que) nós podemos fazer loucuras! Eu juntei o que tinha à minha disposição, e eu enviei-to. Hoje, eu vivo numa casa vazia! A estação está a chegar. Cuida em mandar-me o equivalente aos meus [te]cidos em prata, [no que] constitui a tua parte, para que compre 10 medidas șimdum de cevada. ${ }^{38-48} \mathrm{Em}$ relação à tabuinha com (a lista) das testemunhas de Aššur-imittī, filho de Kura, que ele tomou, ele causou muitos problemas (à) casa e tomou as criadas como penhor, depois os teus representante registaram o negócio. Eu finalmente paguei a dívida de $2 / 3$ de mina de prata para que, até que tu chegues, ele não levante constestações. À tua chegada, vós discutireis sobre isso. Porque é que não deixas de dar ouvidos a calúnias e de me enviares cartas exasperadas?» 


\section{Textos (correspondência de Tarām-kūbi e Šimat-Aššur para Imdílum)}

Fonte: C. MICHEL, Correspondance des Marchands de Kanish, Paris, 2001, 469-470.

\section{Or 50, 101}

«Diz a Imdillum: assim (falam) Tarām-kūbi e Šimat-Aššur. ${ }^{5-18}$ Kutallānum levou-te 6 tecidos nos seu transporte precedente. (Do teu lado) tu enviaste-me uma mina 10 siclos de prata. $E$ desde que tu partiste, tu já não efectuaste mais quaisquer envios. (Se não foi) para mim, a quem então terás tu enviado (somente) uma mina 10 siclos de prata pelos 6 tecidos? (Ao presente), Kutallānum leva-te 6 (novos) tecidos-kutānun. Se tu és meu irmão, tu não deves enviar-me menos de $1 / 3$ de mina! ${ }^{19-28}$ Os teus representantes compraram-te um tecido para Ištat-bāšti, (e) uma casa (que pertence a) Rīm-ilīya, pelo montante de 20 minas de prata. Eles pediram-me a prata e eu dei-o, então, aos teus representantes. Até agora eles ainda não me reembolsaram dizendo: "Nós ainda temos de fazer compras!" ${ }^{28-35}$ se tu és meu irmão, em quem outro poderei eu fiar-me? Eu rezarei diante do meu deus por ti. Kutallānum chegou e tu não mandaste nada (por ele). Eu entreguei 7 siclos de prata a Kutallānum."

\section{TC 1, 5}

«Diz a Imdillum: assim (falam) Tarām-kūbi e Šimat-Aššur. ${ }^{4-17}$ Aqui (em Aššur), nós consultámos os oniromantes, os adivinhos e os espíritos; o deus Aššur não cessa de te prevenir: tu amas (demasiado) o dinheiro e desprezas a tua vida! Não podes tu agradar ao deus Aššur na Cidade (d'Aššur)?, Se faz favor, a partir do momento em que tenhas conhecimento (desta) carta, vem, vai visitar o deus Aššur e salva a tua vida! ${ }^{18-19}$ Porque razão não me envias o preço dos meus tecidos?» 


\section{Mapas: comércio paleo-assírio}

Fonte: G. BARJAMOVIC, "The Geography of Trade Assyrian Colonies in Anatolia c. 1975-1725 BC and the Study of Early Interregional Networks of Exchange", in J. G. DERCKSEN, ed., Anatolia and the Jazira during the Old Assyrian Period, Leiden, 2008, 92-93.

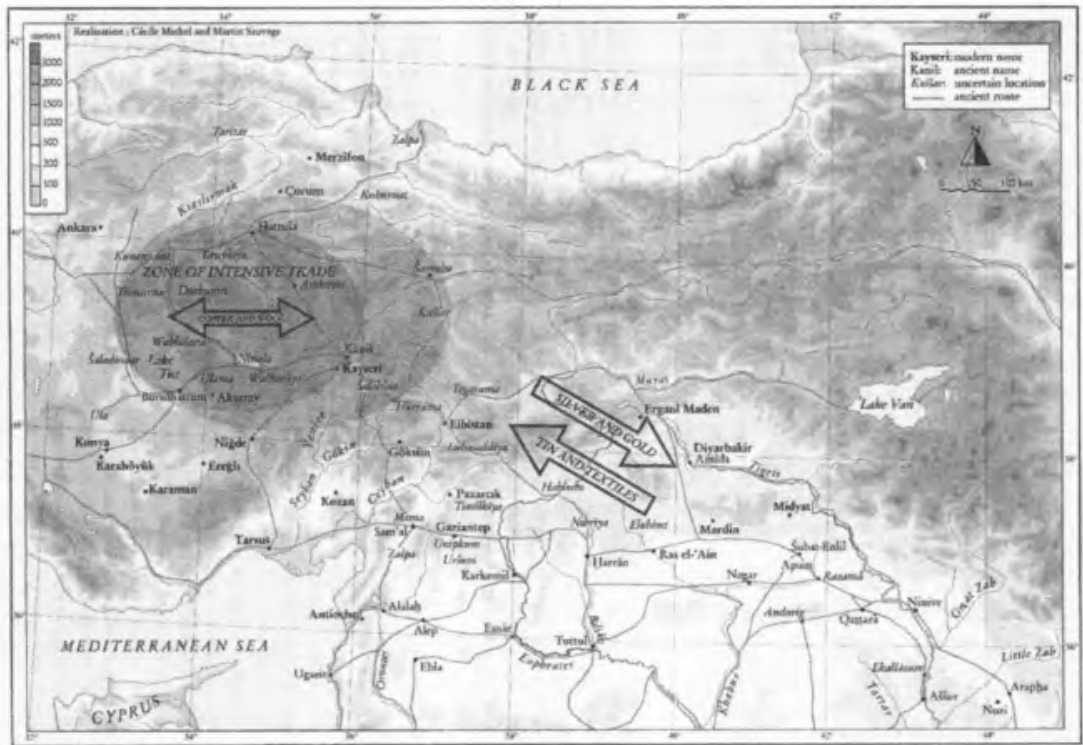

Map 1: Map by C. Michel with overlay: zone of interaction and the model of M. T. Larsen.

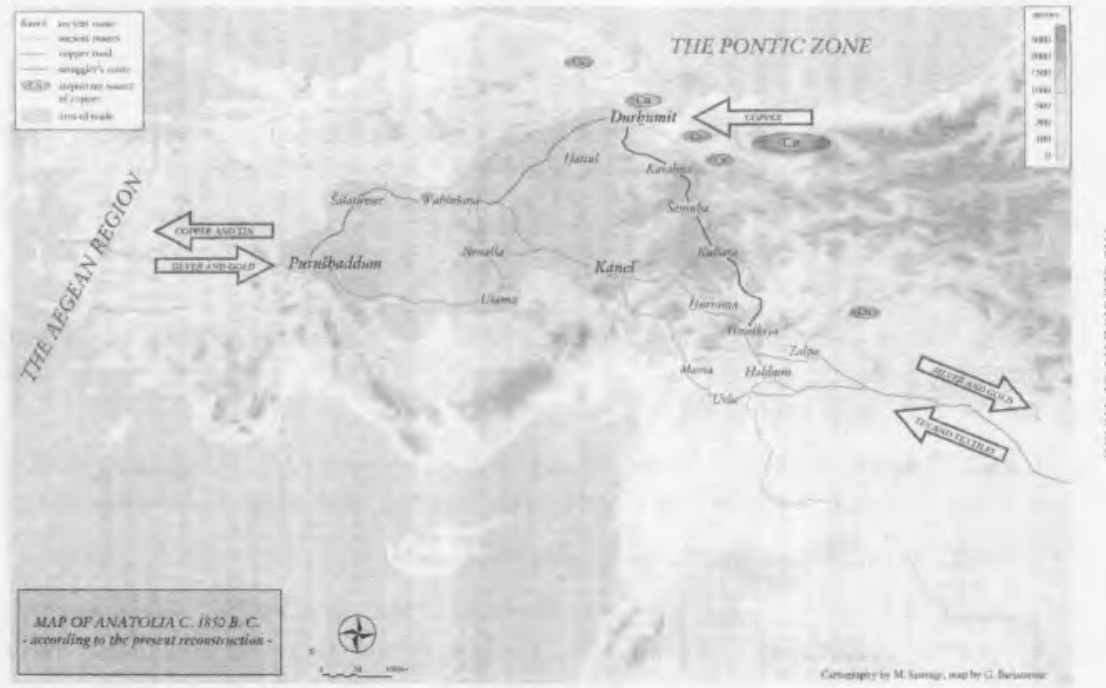




\section{Abreviaturas}

BIN = Babylonian Inscriptions in the Collection of J. B. NIES, New Haven, Part 4, 1927 e Part 6, 1944.

CCT $=$ Cuneiform Texts from Cappadocian Tablets on the British Museum, Londres, Part 3, 1925, Part 4, 1927.

OrNs = Orientalia. Nova série.

TC 1 = G. CONTENAU, Tablettes cappadociennes du Louvre, TCL 4, Paris, 1920.

\section{Notas}

(1) Sobre o comércio paleo-assírio existe uma bibliografia considerável, todavia, refiro apenas a que me parece mais sugestiva no âmbito deste trabalho: M.T. LARSEN, "Commercial networks in the Ancient Near East", in M. Rowlands, M. Larsen, K. Kristiansen eds., Centre and Periphery in the Ancient World, Cambridge, 1987, 47-56; G. BARJAMOVIC, "The Geography of Trade Assyrian Colonies in Anatolia c. 1975-1725 BC and the study of Early Interregional networks of Exchange", in J. G. Dercksen ed., Anatolia and the Jazira during the Old Assyrian Period, NINO, 2008, Leiden, 87-100; C. MICHEL, "Durhumid, son commerce et ses marchands", in D. Charpin, F. Joannès (eds.), Marchands, Diplomates et Empereurs, ERC, Paris, 1991, 253-273; idem, Correspondence des Marchands de Kanish au début $d u{ }^{\circ}$ millénaire avant J.-C. Paris, 2001; idem, Tablettes Paleo-Assyriennes de Kültepe, vol.1, Paris, 1997; idem, Innāya dans les tablettes paléo-assyriennes, vols.I/II, ERC, Paris, 1991; P. GARELLI, Les Assyriens en Cappadoce, Paris, 1963.

(2) G. BARJAMOVIC, op. cit., 88.

(3) Os entrepostos comerciais assírios na Anatólia designavam-se por kärum ou wabartum; ao primeiro corresponde uma "colónia comercial" e ao segundo "uma pequena colónia comercial", de acordo com J. BLACK, et al., A Concise Dictionary of Akadian, Wiesbaden, 2000.

(4) M. T. LARSEN, op. cit, 50 e ss..

(5) O sul da Mesopotâmia viu chegar o cobre da região de Magan (actual Oman), desde o $1 \mathrm{II}^{\circ}$ milénio e a Síria, mais tarde, deverá ter sido abastecida por Chipre.

(6) Op. cit, 95ss.

(7) M. T. LARSEN, op. cit., 53.

(8) As fontes (transliteração para acádico) referentes a Tãram-Kūbi citadas neste trabalho encontram-se em anexo, digitalizadas a partir de C. MICHEL, Innāya dans les tablettes paléo-assyriennes, II, Edition des Textes (v. nota 1).

(9) E. M. TETLOW, Women, Crime, and Punishment in Ancient Law and Society, New YorkJ London, 2004, 119-124; C. MICHEL, Correspondance des Marchands de Kanish, 388.

(10) C. MICHEL, Innãya dans les tablettes paléo-assyriennes, II, 131. KUG 5, p.182.

(11) Para Zalpa existem duas referências geográficas, uma próximo do mar Negro, na regiẫo do Ponto e outra, a sul de Harran, na margen esquerda do rio Balih̆. Ver mapa em Anexos. 
(12) M. VAN DE MIEROOP, Cuneiform Texts and the Writing of History, London and New York, 2006, 93; E. M. TETLOW, Women, Crime, and Punishment in Ancient Law and Society, New York, London, 2004, 119-124.

(13) C. MICHEL, Innāya dans les tablettes paléo-assyriennes, I, 84, n.134.

(14) A ordem pela qual os textos são aqui apresentados exprimem a tentativa de uma cronologia relativa interna, pois não há possibilidade de uma datação precisa para cada um. 